\title{
Toxoplasma gondii: Deeper understanding of epidemiology, virulence and pathophysiology enhances diagnosis and informs vaccine design
}

\author{
Shiferaw Bekele Woyesa ${ }^{1^{*}}$ and Andrew W. Taylor-Robinson ${ }^{2,3}$ \\ ${ }^{1}$ School of Medical Laboratory Science, Institute of Health Science, Jimma University, Jimma, Ethiopia. \\ ${ }^{2}$ Infectious Diseases Research Group, School of Health, Medical and Applied Sciences, Central Queensland University, \\ Brisbane, Australia. \\ ${ }^{3}$ College of Health and Human Sciences, Charles Darwin University, Casuarina, Australia.
}

Received 25 September, 2020; Accepted 01 April, 2021

\begin{abstract}
Toxoplasma gondii is an extremely widespread intracellular obligate parasite that infects both animals and birds. This protozoan pathogen usually causes asymptomatic infection in humans but can cause significant disease in congenitally infected infants, immunodeficient patients and occasionally in immunocompetent individuals. In the complex life cycle of $T$. gondii, sexual development occurs uniquely in felines whereas asexual reproduction may take place in humans and other warm-blooded animals serving as intermediate hosts. The prevalence of infection varies considerably among different geographic areas and also among individuals, depending on a variety of factors, including culinary habits and cleanliness of surroundings. Studies to date show low genetic diversity of $T$. gondii, with three main lineages, designated types I, II and III, found at least within Europe and North America. T. gondii uses various mechanisms to invade host cells and to alter their signal pathways and gene expression. Kinases within the rhoptry, a unique apical organelle, and $T$. gondii granule proteins are key virulence factors that promote attachment to, and invasion of, host cells. Human Toxoplasma infection is acquired by ingestion of raw or undercooked meat that contains tissue cysts, or through the ingestion of water or food contaminated with oocysts. It is also transmitted congenitally from motherto-foetus and less commonly by transfusion of contaminated blood or transplantation of an infected organ. Life-threatening toxoplasmosis can develop in immunocompromised patients. Diagnostic tests are critical to surveillance, control and prevention of toxoplasmosis. However, different technologies presently utilized around the world to detect different parasite stages are not of a uniformly sufficient standard to indicate clearly the epidemiology and severity of infection at global, regional and national levels. While a prophylactic vaccine is licensed for veterinary administration, no similarly efficacious preparation is available to prevent human infections. Here, we review the epidemiology and genotypes of $T$. gondii, as well as current detection methods and the state of vaccine development. In addition, the mechanisms by which this parasitic pathogen invades and overcomes the human immune system are considered.
\end{abstract}

Key words: Toxoplasmosis, Toxoplasma gondii, epidemiology, genotype, virulence, pathophysiology, diagnosis, immunity, vaccine. 


\section{INTRODUCTION}

Toxoplasma gondii is a geographically widely distributed intracellular parasitic protozoan eukaryote. The genus name, Toxoplasma, refers to a bow-shaped organism and derives from two Greek words: 'toxon', which means 'bow'; and 'plasmid', meaning 'form' (Dubey, 2010). T. gondii was first observed in rodents by Nicolle and Manceaux in North Africa and by Splendore in Brazil, both in 1908 (Ferguson, 2009), but it took another 60 years before the parasite was identified as the causative agent of the disease that we now recognize as toxoplasmosis (Dubey, 2008). T. gondii is the only known species associated with toxoplasmosis and about one third of the human population worldwide is infected with this parasite. Humans are infected with $T$. gondii either by eating undercooked or raw meat of animals harbouring tissue cysts or by eating contaminated food and/or drinking contaminated water containing oocysts shed by T. gondii-infected cats (Hill and Dubey, 2002).

In Europe and the United States only 10 to $20 \%$ of cases of $T$. gondii infection in immunocompetent adults and children are symptomatic. However, this proportion may be higher in other regions of the world, such as Latin America. Patients with acute infection may develop cervical lymphadenopathy and influenza-like illness. Rarely, an organ transplant or blood donation recipient is infected by $T$. gondii when they receive an organ or blood from a $T$. gondii-positive donor (Patel and Paya, 1997; Morris et al., 2010; Schwartz, 2013; Bahhaj et al., 2017; White et al., 2018). In immunocompromised patients and during trans-placental infection, toxoplasmosis most frequently causes neurological complications or toxoplasmic encephalitis (McFarland et al., 2016). Congenital toxoplasmosis occurs almost exclusively when a seronegative mother becomes infected during pregnancy but can also develop among immunosuppressed mothers who react to $T$. gondii during pregnancy (Döşkaya et al., 2018; Wallon and Peyron, 2018). In the early 1980s, T. gondii was widely recognized as causing morbidity in immunodeficient patients associated with human immunodeficiency viruscaused acquired immunodeficiency syndrome (HIVIAIDS). This continues to this day as an important diseasecausing agent globally, especially in pregnant women (Döşkaya et al., 2018; Wallon and Peyron, 2018).

This focused review outlines the life cycle, epidemiology, genotypes, virulence, host immune response and pathophysiology of $T$. gondii. Drawing on this information, we discuss how enhancing knowledge of these integrated subjects will facilitate development of improved diagnostic tools and better inform vaccine design against this important yet arguably underresearched global pathogen.

\section{LIFE CYCLE OF T. GONDII}

Toxoplasma is an intracellular obligate parasitic pathogen that is capable of infecting and replicating within any nucleated mammalian or avian cells (Dubey, 2010) and can even alter the host's behaviour to increase its own transmission (Ferguson, 2009; Laing et al., 2020). T. gondii infects most species of warm-blooded animals, including humans. The definitive host is the domestic cat or their relatives (family Felidae), while rodents, particularly mice and rats, act as intermediate hosts (Bahia-Oliveira et al., 2003; Jones et al., 2003).

$T$. gondii can be found anywhere in the world and in humans infection can cause life-threatening encephalitis in immunocompromised individuals such as HIVIAIDS patients or organ transplant recipients (McFarland et al., 2016). Infection acquired during pregnancy may spread into the foetus and cause severe damage to foetal development (Gilot-Fromont et al., 2012; Blader et al., 2015). The $T$. gondii life cycle starts in felids usually through the consumption of infected prey containing tissue cysts. The cyst wall is digested in the stomach and intestines, liberating bradyzoite stage parasites that penetrate the epithelial cells of the small intestine. This initiates the progressive development of asexual and by gametogony sexual forms of the parasite (Figure 1).

The complex life cycle of this pathogenic parasite alternates between feline and non-feline infections where sexual and asexual reproduction takes place, respectively (Morrison and Höglund, 2005). Tachyzoites (tachos $=$ fast) and bradyzoites (brady $=$ slow) are rapidly and slowly growing stages of $T$. gondii, respectively (Dubey, 2002, 2006, 2010). Domestic cats are infected through consuming either sporulated oocysts or intermediate hosts containing tissue cysts (Gilot-Fromont et al., 2012). To be infective, an unsporulated oocyst is converted into a sporulated one within 1-5 days (Black and Boothroyd, 2000; Gilot-Fromont et al., 2012). T. gondii undergoes asexual replication in all warm-blooded vertebrates or in intermediate hosts (Ferguson, 2009). Tachyzoites, also termed endozoites, replicate inside cells for a 6 to $8 \mathrm{~h}$ generation time (observed in vitro) till regress to infect neighbouring cells. This stage may be identified in the blood during acute phase toxoplasmosis (Blader et al., 2015). Tachyzoites multiply slowly in infected host cells and differentiate into bradyzoites

*Corresponding author. E-mail: shiferaw.bekele@ju.edu.et.

Author(s) agree that this artic le remain pemanently open access under the terms of the Creative Commons Attribution License 4.0 Intemational License 


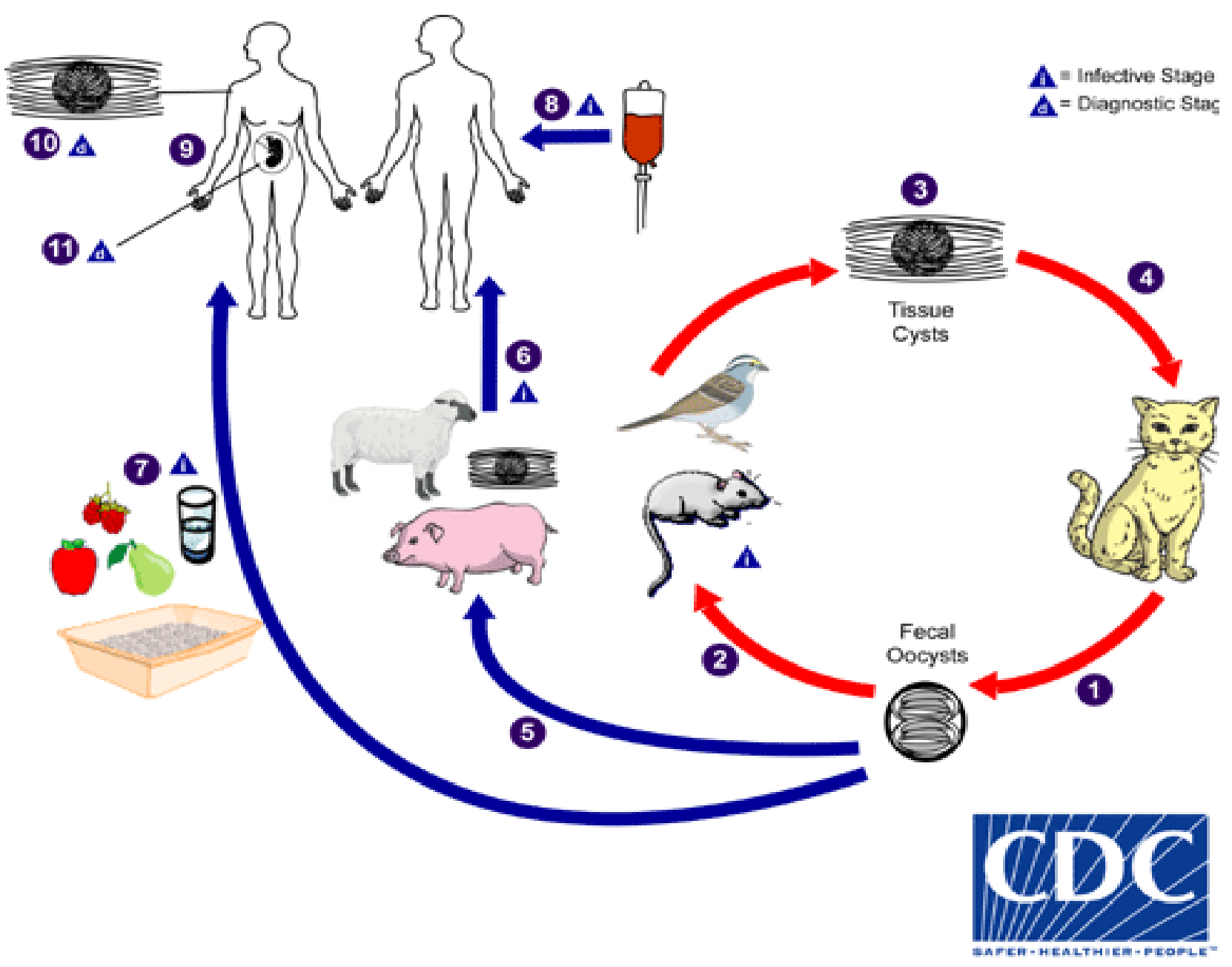

Figure 1. Life cycle of Toxoplasma gondii. The only known definitive hosts for Toxoplasma gondii are members of family Felidae (domestic cats and their relatives). Unsporulated oocysts are shed in the cat's faeces (1). Although oocysts are usually only shed for 1-3 weeks, large numbers may be shed. Oocysts take 1-5 days to sporulate in the environment and become infective. Intermediate hosts in nature (including birds and rodents) become infected after ingesting soil, water or plant material contaminated with oocysts (2). Oocysts transform into tachyzoites shortly after ingestion. These tachyzoites localize in neural and muscle tissue and develop into tissue cyst bradyzoites (3). Cats become infected after consuming intermediate hosts harbouring tissue cysts (4). Cats may also become infected directly by ingestion of sporulated oocysts. Animals bred for human consumption and wild game may also become infected with tissue cysts after ingestion of sporulated oocysts in the environment (5). Humans can become infected by any of several routes: Eating undercooked meat of animals harbouring tissue cysts (6). Consuming food or water contaminated with cat faeces or by contaminated environmental samples (such as faecal-contaminated soil or changing the litter box of a pet cat) (7). Blood transfusion or organ transplantation (8). Transplacentally from mother to foetus (9). In the human host, the parasites form tissue cysts, most commonly in skeletal muscle, myocardium, brain, and eyes; these cysts may remain throughout the life of the host. Diagnosis is usually achieved by serology, although tissue cysts may be observed in stained biopsy specimens (10). Diagnosis of congenital infections can be achieved by detecting $T$. gondii DNA in amniotic fluid using molecular methods such as PCR (12).

Source: Image adapted from Division of Parasitic Diseases and Malaria, US Centers for Disease Control and Prevention. https://www.cdc.gov/parasites/toxoplasmosis/biology.html

(cystozoites) (Weiss and Kim, 2000). In order to remain life-long in their hosts, tachyzoites reside predominantly in brain, eyes, skeletal and cardiac muscle and it takes 7 to 10 days post infection to detect tachyzoites (Black and Boothroyd, 2000; Dubey, 2010).
Tissue cysts develop within the cytoplasm of host cells and they enclose hundreds of crescent-shaped bradyzoites (Morrison and Höglund, 2005). The chronic phase of toxoplasmosis is indicated by development of tissue cysts of the asexual cycle. While digestion is 
ongoing rupturing may happen to cysts ingested with infected tissues. This releases bradyzoites that infect the epithelium of intestinal lumen where they can differentiate back to the rapidly dividing tachyzoite stage to disseminate throughout the body, thereby completing the asexual cycle (Tenter, 2009; Caldas and de Souza, 2018).

\section{T. GONDII HOST CELL INVASION}

Protozoan parasites of the subphylum Apicomplexa, class Sporozoa possess elaborate motility systems that facilitate infection and dissemination. The three infective stages of the complex life cycle of $T$. gondii are sporozoites (inside oocysts), tachyzoites (trophozoites) and bradyzoites (tissue cysts) (Dubey, 2006; Attias et al., 2020). The infective form is the oocyst, which is round to slightly oval in shape measuring 10 to $15 \mu \mathrm{m}$ long by 8 to $12 \mu \mathrm{m}$ wide (Dubey, 2010). This is transparent, containing two sporocysts, each with four sporozoites. The tachyzoite is crescent shaped, more rounded at one end, and ranges in size from 3 to $7 \mu \mathrm{m}$ by 2 to $4 \mu \mathrm{m}$. The bradyzoite appears physically similar to the tachyzoite, but is smaller and viable forms gather in clusters inside the host cell (Ngô et al., 2017). Bradyzoites and tachyzoites differ slightly by location of their nucleus, which is situated towards the posterior end in bradyzoites and more centrally in tachyzoites (Weiss and Kim, 2000). They also differ in contents; bradyzoites contain electrondense rhoptries, several amylopectin granules and they are less susceptible to proteolytic enzyme destruction than are tachyzoites (Morrison and Höglund, 2005; Dubey, 2006; Hakimi et al., 2017).

Parasitic motility and secretory organelle proteins of $T$. gondii are involved in host cell invasion (Carey et al., 2004; Jones et al., 2017). Attachment of $T$. gondii to the host cell membrane requires secretion of adhesins that recognize receptors and promote parasite re-orientation for attachment (Bonhomme et al., 1999; RobertGangneux and Dardé, 2012). Calcium stored intracellularly by $T$. gondii supports the parasite to secrete molecules that facilitate motility and invasion of host cells (Lovett and Sibley, 2003; Randall and Hunter, 2011). Micronemes are used to secrete adhesins that are required by the parasite life cycle to span egress, move to a new host cell and to subsequently invade (Blader et al., 2015). Toxoplasma rhoptry neck protein4 is a component of the moving junction macromolecular complex of $T$. gondii that plays a central role during host cell invasion and interacts specifically with the host cell cytoskeleton in parasite-infected cells (Takemae et al., 2013).

The motile and invasive stages of $T$. gondii contain a unique organelle called a glideosome (Weiss and Dubey, 2009). Composed of actomyosin, the glideosome promotes substrate-dependent gliding motility that powers migration across biological barriers and also drives the parasite's entry into and egress from infected cells (Kappe et al., 2004). The invasive stages of $T$. gondii are able to actively penetrate host cells to maintain an intracellular life style and they are highly motile, moving rapidly on solid substrates; however, they have no special structures such as cilia, pseudopods or flagella for locomotion (Daher et al., 2010). The cellular features that define the unique adaptation of apicomplexan parasites like $T$. gondii were revealed by electron microscopy and include two distinct types of organelle, club-shaped rhoptries and surrounding small, rod-shaped micronemes, both of which perform an important secretory function during invasion of host cells (Hakimi et al., 2017).

T. gondii rhoptry proteins (ROPs) are presented first to the host immune system and thus constitute key molecules for Toxoplasma immunodiagnosis and immunoprophylaxis (Dlugonska, 2008; Zhang et al., 2018). Long non-coding RNAs (IncRNAs) are nonprotein-coding transcripts of greater than 200 nucleotides that regulate gene expression yet little is known about their role in response to infection by intracellular pathogens including $T$. gondii. However, recently it was hypothesized that $T$. gondii regulates IncRNA molecules to modify the host immune response (Menard et al., 2018). Upon host cell invasion, ROPs secreted by $T$. gondii produce active protein kinases that exert a longlasting effect on intracellular development and virulence towards the host (El Hajj et al., 2007; Etheridge et al., 2014). Rhoptry secretory products also prevent the parasitic pathogen from exposure to lysosomal fusion by altering the parasitophorous vacuole membrane (Randall and Hunter, 2011).

\section{EPIDEMIOLOGY AND RISK FACTORS FOR TOXOPLASMOSIS}

T. gondii infects about 30 to $50 \%$ of human populations worldwide and more than one million cases of infection contracted through drinking oocyst-contaminated water or eating tissue cyst-contaminated food, primarily raw or undercooked pork and lamb, are reported every year in Europe alone (WHO, 2015). Hence, although it is extremely prevalent in low-income countries this widespread distribution means that toxoplasmosis not considered as a classic 'disease of poverty'. Globally, geographical differences and food cultural habit variation from one country to another, even from one area to another within the same country, contribute greatly to regional variation in prevalence of $T$. gondii human infection. In particular, food cultural variation among ethnic groups in the same location is the main reason for their different observed rates of infection of $T$. gondii. For 
instance, the highest prevalence of toxoplasmosis was reported from France (54.3\%) when compared with other European countries in earlier studies (Serranti et al., 2011). A two-year survey in the US revealed the seroprevalence of $T$. gondii among persons $\geq 6$ years was $13.2 \%$, and the age-adjusted prevalence was $12.4 \%$, with the largest prevalence (9.1\%) among women in the 15 to 44 years age group (Jones et al., 2014). Data analyzed for 19 years (1995-2008) from 88 countries, 29 of which were in Europe, indicated the correlation of toxoplasmosis with specific diseases burden estimated as age-standardized disability adjusted life years (DALYs) and also with mortality of women of childbearing age. According to this published survey, the prevalence of toxoplasmosis correlated with 23\% of various diseases burden in Europe (Flegr et al., 2014).

Studies conducted for 16 years at three intervals (19881994, 1999-2004 and 2009-2010) among US women of child-bearing age (15-44 years) revealed a declining ageadjusted prevalence of toxoplasmosis (15, 11 and 9\%) from earliest to most recent years. These findings indicate that there was an incremental increase in awareness over time to control toxoplasmosis transmission (Maldonado and Read, 2017). Some African nations reported highest prevalence of toxoplasmosis among child-bearing age women that indicates the highest rate of transmission and lack of awareness to control toxoplasmosis. For instance, the prevalence of toxoplasmosis among child-bearing age women reported from Ghana was 92.5\% (Ayi et al., 2010). T. gondii infects children not only after birth but also congenitally in utero. Between 40 and 400 children born each year in Canada are infected congenitally by $T$. gondii (University of Guelph Centre for Public Health and Zoonoses, 2009).

The highest seroprevalence of $T$. gondii has been reported from developing countries like Ethiopia. For example, the seroprevalence of $T$. gondii recorded in northern Ethiopia was 76.5\% (Muluye et al., 2013). The prevalence of toxoplasmosis was similar among pregnant women with previous histories of normal delivery and abortion (21.5\% vs. $24.6 \%$, respectively) (Saki et al., 2015). An investigation in Sudan showed the highest prevalence of $T$. gondii among HIV patients (75\%), then aborting women $(58.3 \%)$ and suspected cases of $T$. gondii (55.5\%) (Mohamed et al., 2013). There is a risk of toxoplasmic encephalitis in HIV-positive patients and among HIV-negative immunosuppressed patients. Hence, immune status improvement among immunosuppressed patients such as those with HIVIAIDS reduces the chance of being infected by $T$. gondii. For instance, studies from Iran on HIVIAIDS patients indicated a reduction of prevalence of toxoplasmosis (from $49.75 \%$ ) by more than $50 \%$ over several years based on improvement of the immune status of patients (Mohraz et al., 2011; Foroutan et al., 2018).
A study reported from Germany indicated that being in frequent contact with domestic cats and male obesity (body mass index $\geq 30 \mathrm{~kg} / \mathrm{m}^{3}$ ) were independent predictors to acquire $T$. gondii infection. Similarly, the rate of $T$. gondii infection increased with age of individuals (20\% among $18-29$ age group versus $77 \%$ among $70-79$ age group) (Wilking et al., 2016). Similar research findings reported from China indicated that keeping cats at home and consuming undercooked or raw meat were independent risk factors for high prevalence of toxoplasmosis in patients with different types of diabetes (21.25, 16.5 and $23.5 \%$ in type 1, type 2 and gestational diabetes, respectively) (Li et al., 2018). Various studies reported higher prevalence of $T$. gondii in diabetic patients, although there were variations in detection of different classes of antibody produced against Toxoplasma infection (Majidiani et al., 2016). For instance, a study reported from Egypt showed that 45.0 and $5.0 \%$ seroprevalence of $T$. gondii detected by antiimmunoglobulin (Ig)G and anti-IgM), respectively, in type 1 diabetic patients (Khattab et al., 2019). Reports from Iran indicated that chronic toxoplasmosis was a risk factor for type 2 diabetes mellitus (Colli et al., 2010), but there was no statistical relationship between serum levels of anti-T. gondii antibodies and the risk for diabetes mellitus (Khalili et al., 2018). In general, the reason for high seroprevalence of $T$. gondii infection among diabetic patients and the mechanism by which toxoplasmosis relates to diabetes mellitus are not clearly defined.

Toxoplasmosis is more common in domestic animals than it is in humans. A study conducted in China for 18 years (2000-2017) reported that toxoplasmic infection was about four times more likely to occur in domestic animals than in humans (23.4\% versus $8.2 \%$ ) (Dong et al., 2018). A similar study conducted in seven Chinese regions reported high seroprevalence of $T$. gondii among meat-producing animals, with pigs, chickens and cattle having a 24,20 and $9.5 \%$ rate of infection, respectively (Deng et al., 2018).

\section{TOXOPLASMA GENOTYPES AND VIRULENCE}

It is challenging to draw conclusions about $T$. gondii genotypic virulence due to its genomic diversity; however, most genotypes isolated are virulent in mice (Dardé, 2008). Defining the pattern of genetic diversity is very important to understand the worldwide distribution of $T$. gondii. Numerous data have been published on genotypes of $T$. gondii, primarily in Europe, South and North America but with notably less information from Asia and Africa (Chaichan et al., 2017). T. gondii has been described as having low genetic diversity and a clonally low population structure. The most exhaustive studies have identified as few as six major population clades, or lineages, although detailed sequence analysis indicates 
that there is a varied amount of genetic exchange within and between these. The first genotyping studies to isolate a $T$. gondii strain took place concurrently in France and the USA, with three main lineages designated as type I, II and III that may identify clinically relevant biological differences. These lineages are found predominantly in Europe and North America.

Genotypes not belonging to the three main lineages are found predominantly in other continents. A few years after isolation of the three lineages in other continents, type II and III were identified in Africa. Studies conducted more recently showed lineage type II was found predominantly in East and North Africa; however, there was no specific region identified in Africa for type III (Galal et al., 2018). Based on genotypic characterization, type I and II $T$. gondii strains were determined among $52 \%$ and $75 \%$ of immunosuppressed and congenital toxoplasmosis cases, respectively (Fuentes et al., 2001). Chinese 1 or ToxoDB\#9 genotypes were identified in China from pigs intended for human consumption, with $11.26 \%$ prevalence (Wang et al., 2016). Understanding strain diversities between human and animal $T$. gondii pathogens is an essential requirement to distinguish potential virulence strains. Further mouse model studies conducted in China isolated another genotype, ToxoDB\#205, and suggested a significant difference in mouse mortality rates from infection by Chinese isolates and the archetypal I, II, III strains (Gao et al., 2017).

The polymorphism of rhoptries and micronemes between different strains of $T$. gondii appear responsible for many of the differences in virulence seen for types I, II and III in mice. By inoculating tachyzoites into animal models (especially laboratory mice) experimental studies from several countries identified comparable virulence of different $T$. gondii genotypes within a week postinoculation. For instance, ToxoDB genotype \#13 from the Caribbean had a level of virulence similar to that of ToxoDB genotype \#6 from Brazil in killing infected mice within 8 days (Hamilton et al., 2019). The link between different $T$. gondii molecules, including ROPs (Kappe et al., 2004; Schwartz, 2013; McFarland et al., 2016) and dense granules (Bahhaj et al., 2017), is less recognized. However, a Chinese study indicated a linkage between these molecules to strain virulence, demonstrated as a reduced immune response by mice to the parasite and variation in some key genes among the same genotypes of the parasite (Cheng et al., 2017). T. gondii strains isolated from South America are genetically more diverse than strains from other regions (Alruhaili, 2015); however, Brllineage was the only genotype identified in Brazil (Pena et al., 2013). ToxoDB genotype 6 reported from Brazil is highly virulent to mice whereas all predominant genotypes from the northern hemisphere are intermediately virulent or non-virulent to mice (Shwab et al., 2018). A large genetic diversity of $T$. gondii is highly virulent to humans and experimental animals. For example, from $27 T$. gondii isolates determined in Brazil among patients with known congenital toxoplasmosis, about $25.9 \%$ were previously identified genotypes in animals (Carneiro et al., 2013). T. gondii type I strain is predominantly identified from HIV patients (about 80\%) and ocular toxoplasmosis cases (Fekkar et al., 2011). Intensively focusing on an individual gene or protein of $T$. gondii is a traditional approach to discovering new treatments for toxoplasmosis. However, a gene regulatory network has been reconstructed to emulate the life cycle of $T$. gondii and this new strategy helped researchers to predict 25 new pathogenic factors and a small gene circuit that drives a series of phenotypic transitions which characterize the life cycle of this pathogen (Alonso et al., 2019).

The major histocompatibility complex class II gene DQS has been significantly associated with the development of toxoplasmic encephalitis in North American white AIDS patients, and HLA-DQS was also significantly associated with the development of hydrocephalus in children with congenital toxoplasmosis (Schlüter and Barragan, 2019). In one recent Brazilian study certain HLA-DQA1 and HLA-DQB1 alleles were associated with congenital infection (Shimokawa et al., 2016).

\section{IMMUNE-MEDIATED CONTROL OF T. GONDII}

Microorganisms exhibit a variety of mechanisms to invade their host. Intracellular pathogens like $T$. gondii make the use of the host cell's machinery within which to replicate. However, successful resistance to an invading infectious agent is largely governed by the host's capacity to mount an appropriate protective immune response. Therefore, analysis of such interactions between the host immune system and invading microorganisms requires a broad spectrum of immunological methods. In order to recognize toxoplasmosis and to detect the structural components of $T$. gondii, host immune sensors produce pro-inflammatory cytokines and chemokines (Fisch et al., 2019). Antigen-presenting cells (macrophages and dendritic cells, DCs) strongly activate and induce development of $\mathrm{CD} 4^{+} \mathrm{T}$ helper 1 (Th1) cells and antigen-specific cytotoxic $\mathrm{T}$ cells $\left(\mathrm{CD}^{+}{ }^{+} \mathrm{T}\right.$ cells) to produce interferon (IFN)-g which in turn stimulates cellautonomous immunity in cells infected by $T$. gondii (Kim et al., 2006; Gov et al., 2013; Garcia et al., 2014; Brasil et al., 2017; Krishnamurthy et al., 2017; Sander et al., 2018; Sasai et al., 2018).

While the detailed mechanisms by which immunity to $T$. gondii can be driven in differing directions, either more or less inflammatory, may be distinct to humans much of what is known about broad aspects of the host immune response has arisen through elegant use of murine study conducted in mice by inactivating toll-like receptor 
(TLR) adaptor protein myeloid differentiation primary response gene 88 (MyD88) in different innate cell types showed that lack of MyD88 in DCs, but not in macrophages or neutrophils, resulted in high susceptibility to $T$. gondii infection. Thus, the results demonstrate that DCs play a central role in coordinating the innate immune response to an intracellular pathogen and its defect in pathogen recognition can predetermine sensitivity to the infection (Hou et al., 2010). White blood cell indices including leukocytes, natural killer (NK) cells and monocyte counts revealed a decrease among immunosuppressed male but not female patients infected by T. gondii (Flegr and Stříž, 2011).

In order to understand more about the role of T cells in developing immunity against $T$. gondii infection, peripheral blood mononuclear cells from $T$. gondii seropositive individuals were used to generate antigenspecific $T$ cell clones. According to the findings of this study, there was evidence for the existence of circulating antigen-specific $\mathrm{CD}^{+} \mathrm{T}$ cells in healthy humans who are Toxoplasma antibody-seropositive (Khan et al., 1990). T. gondii infection contributes greatly to the reduction of lymphocyte subsets (B cells, NK cells, $\mathrm{CD} 4^{+}$and $\mathrm{CD}^{+}{ }^{+}$ cells) in HIV-infected individuals (Beran et al., 2015). Rhoptry kinases and pseudokinases secreted by $T$. gondii alter the signaling pathways and gene expression of many hosts (Hakimi et al., 2017). The pathway by which the innate immune response recognizes $T$. gondii in the definitive host (mouse) is quite different from in the intermediate host (human). This reflects the differing roles of the two hosts in the biology of the parasite. The innate cytokine response to $T$. gondii in the mouse requires stimulation of TLRs by a soluble parasite ligand whereas in humans it requires phagocytosis of the live pathogen (Sher et al., 2017). T. gondii possesses host immune-modulating proteins; the immune-modulatory activity of macrophage migration inhibitory factor of $T$. gondii (TgMIF) helps the parasite to sustain its survival within the human (Sommerville et al., 2013). NK cells have multiple and complex roles including acute toxoplasmosis control, inflammation regulation via interleukin (IL)-10 and adaptive memory-like responses at all stages of immunity (Gigley, 2016).

Micronemes, rhoptries and dense granules are the major secretory products of $T$. gondii that mediate surplus effects on host signaling pathways to establish chronic infections in humans (Pollard et al., 2009) by targeting primarily host apoptotic pathways (Mammari et al., 2019). T. gondii can invade NK cells directly, which alters NK migration to produce a hyper-motile phenotype. However, the consequences of this phenotype for dissemination of $T$. gondii into the brain remain unknown. Similarly, a mouse study found no evidence for a role for hypermotile NK cells in delivery of parasites to the brain during acute infection with $T$. gondii (Petit-Jentreau et al., 2018). In order to disseminate effectively within host cells many intracellular pathogens first infect leukocytes, which they use as a vehicle to transport them to target organs. For instance, once $T$. gondii is at the target organ, it can cross the capillary wall in its extracellular form by infecting endothelial cells although it may then face the risk of host immune attack after egression from leukocytes. However, adhesion of tachyzoite-infected leukocytes to endothelial cells triggers immediate egression of the parasite from its vehicle leukocyte, enabling it to time this to coincide with arrival at a target organ, thereby minimizing the opportunity for immune attack during the transition from a vehicle leukocyte to capillary endothelial cells (Baba et al., 2017). Infecting mice with $T$. gondii tachyzoite extracts prevented their development of allergies. This suggests that extracts derived from $T$. gondii may replicate the benefits of parasitic infection, offering new therapies for immunemediated disorders (Drinić et al., 2017).

$T$. gondii is a life-threatening opportunistic parasite in AIDS patients. During HIV infection, human plasmacytoid DCs (pDCs), the major source of IFN- $\alpha$ (an antiviral cytokine), decrease in circulation and produce less IFN- $\alpha$ in response to viral stimulation. However, a study conducted to investigate the impact of $T$. gondii coinfection with HIV on innate virus-directed responses of human pDCs showed that IFN- $\alpha$ production was inhibited only in cells infected by $T$. gondii, which implies that suppression of pDCs is activated by $T$. gondii (Pierog et al., 2018). It is tachyzoite phagocytosis rather than host cell invasion that is required for human host cytokine induction (Tosh et al., 2016). Patients with different types of toxoplasmosis exhibit different immune response mechanisms to $T$. gondii antigen. Production of IL-2 and IFN-g by peripheral blood mononuclear cells from patients with congenital toxoplasmosis toward soluble Toxoplasma tachyzoite antigen was reduced compared to from patients with acquired toxoplasmosis. Furthermore, this study revealed that susceptibility to ocular lesions following acquired toxoplasmosis is associated with high levels of IL-1 and tumour necrosis factor- $\alpha$, whereas resistance is associated with high levels of IL-12 and IFN-g (Yamamoto et al., 2000).

\section{PATHOPHYSIOLOGY OF TOXOPLASMOSIS}

Toxoplasmosis can be acquired or congenital. Acquired toxoplasmosis is usually asymptomatic or can manifest as influenza-like symptoms in immunocompetent individuals in which typically it does not have lasting ill effects but is estimated to cause 3 to $7 \%$ of clinically significant lymphadenopathy (Jones et al., 2017). Severe life-threatening toxoplasmosis may develop in immunosuppressed patients due to reactivation of latent infection (Bessieres et al., 2009). During pregnancy, $T$. gondii is transmitted congenitally, mother-to-foetus, to 
which infection can cause severe damage including brain calcification, hydro-encephalitis, vision disorders and still birth or abortion (Roberts et al., 2001; Pleyer et al., 2014; Brasil et al., 2017; Jones et al., 2017). The prevalence of congenital toxoplasmosis in different communities ranges from 0.1 to 1.0 cases per 1,000 live births (Yıldız et al., 2015), and ophthalmological and neurological disabilities are the most important consequences of congenital toxoplasmosis (Blader et al., 2015).

Toxoplasmosis causes a severe visual handicap and blindness in young people (Rothova, 2003). Congenital toxoplasmosis (CT) is a serious, sometimes fatal disease in immunosuppressed individuals which develops during pregnancy due to pregnancy-related immunosuppression or reactivation of the parasite from previous infection of an immunocompetent mother. CT causes miscarriage (stillbirth) or hearing, visual and cognitive problems to the child (Frenkel, 1974; Rothova, 2003; Maldonado and Read, 2017). Approximately 70 to $90 \%$ of patients with CT and 10 to $12 \%$ of patients with postnatal toxoplasmosis develop ocular toxoplasmosis (OT), which is the most common cause of retinitis (Dardé, 2008). OT is either acquired or caused by reactivation of congenital infection (Pleyer et al., 2014). Toxoplasmic encephalitis (TE) is the leading cause of mortality in HIV-infected patients (Rothova, 2003). A study from Cameroon reported a $29.9 \%$ mortality rate from $14.4 \%$ of HIVIAIDS patients admitted to a single hospital with TE (Luma et al., 2013). The global incidence of TE is very rare but one US case in a haematopoietic stem cell transplantation recipient (Kollu et al., 2018) and another case for an HIV seropositive patient in South Korea (Lee and Lee, 2017) have been reported.

$T$. gondii is one of the world's most successful parasites due to its unique ability to persist in the central nervous system of a variety of hosts (Ngô et al., 2017). $T$. gondii cannot withstand lysosomal degradation per se; however, it triggers prolonged epidermal growth factor receptor signaling of autophosphorylation in order to avoid autophagic targeting and to promote its survival in hosts (Corcino et al., 2019). An experimental study conducted by infecting rodents with $T$. gondii indicated increased dopamine production in rodent brain cells encysted with the parasite and host behavioral changes due to the surplus dopamine (McConkey et al., 2013). Several epidemiological studies have suggested an association between infection with $T$. gondii and schizophrenia and other mental illnesses, but a definition etiological role of the parasite in such psychiatric disorders has not been established (Sutterland et al., 2015; Flegr and Horáček, 2018; Burgdorf et al., 2019).

\section{MEDICAL LABORATORY DIAGNOSIS}

Detection of $T$. gondii is mandatory to the surveillance, prevention and control of toxoplasmosis globally (Szabo and Finney, 2017). Physicians may consider the diagnosis of toxoplasmosis in light of a patient's clinical presentation. The usefulness of a given diagnostic method may differ considerably with the clinical category, be that toxoplasmosis in the immunocompetent or immunodeficient patient, ocular toxoplasmosis, toxoplasmosis in pregnancy or congenital toxoplasmosis. For each of these the utility of serological tests should be relevant to context; for instance, demonstration of tachyzoites in tissues or body fluids, amplification of $T$. gondii DNA or isolation of the parasite in body fluids, demonstration of $T$. gondii tissue cysts in the placenta, foetus or neonates (Dard et al., 2016; Soares and Caldeira, 2019). Traditional approaches to detecting toxoplasmosis such as immunological and imaging techniques are still used for routine diagnosis. The most advanced test methods currently used to diagnose $T$. gondii are polymerase chain reaction (PCR)-based molecular techniques and polymorphic polypeptide-based serotyping methods. The first technique is used to amplify $T$. gondii nucleic acids, while the second is used to serotype $T$. gondii in both humans and animals (Barker and Holliman, 1992; Liu et al., 2015; Gomez et al., 2019). Enzyme-linked immunosorbent assays (ELISA) using recombinant proteins were developed to diagnose recent acute toxoplasmosis. For this purpose, oral administration of $T$. gondii tissue cysts and oocysts to mice to evaluate diagnostic values of sporozoite- and bradyzoite-specific proteins showed the validity of recombinants markers to detection (Döşkaya et al., 2014).

$T$. gondii stage-specific antigens can improve the diagnosis of recent acute toxoplasmosis in serological assays. Analysis of both pooled sera collected from mice orally infected with oocysts and tissue cysts, and from patients with toxoplasmosis, determined the abundance of antigens with strong immunogenicity in mouse and human antibodies profiles that could be used to inform development of a vaccine or serological diagnostic assay (Döşkaya et al., 2018). Detecting serological markers is a method of choice to determine $T$. gondii in patients suspected of toxoplasmosis. However, it is difficult to determine directly the presence of $T$. gondii parasites in the human body (Schaefer et al., 2012). Different antibodies are produced against $T$. gondii and their concentration levels in host peripheral blood may rise or fall over time after infection (Montoya, 2002). Anti-IgM and anti-IgG antibodies are specific markers for current toxoplasmosis; however, they may lead to misdiagnosis in recovering patients due to their persistence in the blood after treatment (Colli et al., 2010). A combination of serology-based methods or serological Toxoplasma test panels including the Sabin-Feldman dye test, double sandwich IgM ELISA, IgA ELISA and IgE ELISA are recommended to identify whether or not $T$. gondii 
infection is current (Montoya, 2002). Determination by ELISA of $T$. gondii-specific $\lg A, \lg E, \lg M$ and $\lg G$ antibodies, as well as IgG avidity, and confirmation of results by immunoblot provides strong support for this method to routinely diagnose $T$. gondii.

Since detection of specific antibodies in sera is not always sufficiently accurate and to enable precise definition of the stage of $T$. gondii infection, searching for $T$. gondii stage-specific molecular markers offers great value to distinguishing acute or chronic toxoplasmosis. Shared by all apicomplexan invasive stages, ROPs are essential to parasite propagation (Dubremetz, 2007). ROP5 and ROP18 proteins of $T$. gondii are specific for anti-IgM and anti-IgG to diagnose human toxoplasmosis (Grzybowski et al., 2015). Amplification by PCR of specific nucleic acid sequences from body fluid and tissue samples has been used successfully to diagnose congenital (Bessières et al., 2009), ocular (Gomez et al., 2019), cerebral and disseminated toxoplasmosis (Rasti et al., 2012). While the Sabin-Feldman dye test is considered a gold standard assay to detect $T$. gondii in serum it requires fresh viable tachyzoites that makes it the method the most difficult to perform. Tachyzoites are typically supplied from infected laboratory mice and rats that are not accessible to diagnostic hospitals (Evans et al., 1999). A variety of cell lines and culture methods are used for $T$. gondii antigen production and for therapeutic and genetic studies.

Immunofluorescence and enzyme immunoassay are the most commonly used routine tests to detect anti-lgG and anti-IgM secreted during toxoplasmic infection although $T$. gondii-specific IgM testing lacks specificity. Detection of $T$. gondii-specific IgA is more sensitive than that of IgM in babies infected congenitally (Gomez et al., 2018), but serological determination of active infection of the central nervous system of immunosuppressed patients is not possible (Evans et al., 1999).

\section{VACCINE DEVELOPMENT}

Currently, there is no licensed commercial vaccine to prevent $T$. gondii infection of humans, so in order to avoid toxoplasmosis transmission, particularly in seronegative pregnant women and immunodeficient patients, a number of preventive measures can be taken. These include: cooking meat to a safe temperature (that is, one sufficient to kill $T$. gondii); peeling or thoroughly washing fruit and vegetables before eating; cleaning cooking surfaces and utensils after they have contacted raw meat, poultry, seafood, or unwashed fruit or vegetables; pregnant women avoiding changing pet cat litter or, if no one else is available to change the litter, using gloves, then washing hands thoroughly; and not feeding raw or undercooked meat to pet cats and keeping them inside to prevent acquisition of $T$. gondii by eating infected prey
(Hampton, 2015; Rajapakse et al., 2017).

Vaccines are prepared against infectious disease agents utilizing a variety of immunization strategies and delivery platforms. These include using whole diseasecausing microorganisms, some of their components or genetic modification by the process of weakening living organisms through cultivation (live-attenuated vaccine). Vaccines may be also produced through the process of inactivating whole organisms by chemicals, heat treatment or other means (inactivated vaccine) (Karch and Burkhard, 2016). Vaccination against viral and bacterial pathogens is a widespread, routine and successful practice; however, to date none is successful against a protozoan pathogen of humans (Pinzan et al., 2015; El Bissati et al., 2016; Hu et al., 2017; Wang et al., 2017; Hajissa et al., 2019).

Vaccines prepared from $T$. gondii stage-specific antigens are thought to be pivotal to stage-specific protection. Leading modern vaccine design strategies for T. gondii include epitope mapping to design multi-epitope vaccines, live-attenuated vectors as vehicles for delivery and expression of an antigen, and heterologous primeboost regimens (Hu et al., 2017; Foroutan et al., 2019). A very large number of around 1,360 protein families have been described as potential targets to develop a vaccine against $T$. gondii infection. Among these, surface antigen glycoproteins are considered crucial to host cell attachment and host immune evasion (Garcia et al., 2014). Activation of protein-coding genes including TLR4 and TLR5 that trigger human $T$ cells to prevent toxoplasmosis could be a promising vaccine strategy (EI Bissati et al., 2017).

For more than two decades efforts have been made to develop a vaccine against $T$. gondii in animals to reduce oocyst shedding in cats and tissue cyst formation in mammals. Nevertheless, so far only a live-attenuated vaccine based on the S48 strain has been licensed for veterinary use (Zhang et al., 2013). In a concerted drive to find a $T$. gondii vaccine, more than one hundred experimental studies were reported for the five-year period 2009-2013. In $78.0 \%$ of these investigations a mouse model was exploited, followed by sheep and pigs in 5.5 and $1.8 \%$ of studies, respectively (Garcia et al., 2014). Superoxide dismutase produced by $T$. gondii is very important for bradyzoite and tachyzoite stages to grow within host cells. A mouse model study revealed that a vaccine developed from $T$. gondii DNA elicited strong parasite-specific humoral and cellular immune responses, so superoxide dismutase has been suggested as a potential candidate for future $T$. gondii vaccine development (Liu et al., 2017; Zhang et al., 2019).

\section{CONCLUSION}

T. gondii is the most commonly occurring intracellular 
protozoan parasite in the world. Despite numerous studies having been conducted on toxoplasmosis over many years, the prevalence of $T$. gondii in humans remains unacceptably high. Potentially virulent genotypes from many different countries remain poorly studied and are thus not elucidated clearly. A deeper understanding of the virulence mechanisms and pathophysiology of this obligate intracellular pathogen will not only improve diagnosis but is an essential prerequisite to successful vaccine design and drug discovery.

\section{CONFLICT OF INTERESTS}

\section{The authors have not declared any conflict of interests.}

\section{REFERENCES}

Alonso AM, Corvi MM, Diambra L (2019). Gene target discovery with network analysis in Toxoplasma gondii. Scientific Reports 9(1):1-14.

Alruhaili MH (2015). Genetic diversity of African isolates of Toxoplasma gondii. PhD thesis, University of Salford, UK.

Attias M, Teixeira DE, Benchimol M, Vommaro RC, Crepaldi PH, De Souza W (2020). The life-cycle of Toxoplasma gondii reviewed using animations. Parasites and Vectors 13(1):1-13.

Ayi I, Edu S, Apea-Kubi KA, Boamah D, Bosompem KM, Edoh D (2010). Sero-epidemiology of toxoplasmosis amongst pregnant women in the greater Accra region of Ghana. Ghana Medical Journal 43(3).

Baba M, Batanova T, Kitoh K, Takashima Y (2017). Adhesion of Toxoplasma gondii tachyzoite-infected vehicle leukocytes to capillary endothelial cells triggers timely parasite egression. Scientific Reports 7(1):1-9.

Bahhaj R, Ahmadpour E, Mahami-Oskouei M, Fallah E, Shamsasenjan $\mathrm{K}$, Safaiyan A (2017). Toxoplasma gondii infection and related risk factors among blood donors in northwest Iran. Archives of Clinical Infectious Diseases 12(2): e62005.

Bahia-Oliveira LMG, Jones JL, Azevedo-Silva J, Alves CC, Oréfice F, Addiss DG (2003). Highly endemic, waterborne toxoplasmosis in north Rio de Janeiro state, Brazil. Emerging Infectious Diseases 9(1):55.

Barker KF, Holliman RE (1992). Laboratory techniques in the investigation of toxoplasmosis. Genitourinary Medicine 68(1):55-59.

Beran O, Kodym P, Maly M, Davidova A, Reinvartova G, Jilich D, Rozsypal H (2015). The effect of latent Toxoplasma gondii infection on the immune response in HIV-infected patients. Biomed Research International 2015:271842

Bessieres MH, Berrebi A, Cassaing S, Fillaux J, Cambus JP, Berry A, Magnaval JF (2009). Diagnosis of congenital toxoplasmosis: prenatal and neonatal evaluation of methods used in Toulouse University Hospital and incidence of congenital toxoplasmosis. Memórias do Instituto Oswaldo Cruz 104(2):389-392.

Black MW, Boothroyd JC (2000). Lytic cycle of Toxoplasma gondii. Microbiology and Molecular Biology Reviews 64(3):607-623.

Blader IJ, Coleman BI, Chen CT, Gubbels MJ (2015). Lytic cycle of Toxoplasma gondii: 15 years later. Annual Review of Microbiology 69:463-485.

Bonhomme A, Bouchot A, Pezzella N, Gomez J, Le Moal H, Pinon JM (1999). Signaling during the invasion of host cells by Toxoplasma gondii. FEMS Microbiology Reviews 23(5):551-561.

Brasil TR, Freire-de-Lima CG, Morrot A, Vetö Arnholdt AC (2017). HostToxoplasma gondii coadaptation leads to fine tuning of the immune response. Frontiers in Immunology 8:1080

Burgdorf KS, Trabjerg BB, Pedersen MG, Nissen J, Banasik K, Pedersen OB, Ullum H (2019). Large-scale study of Toxoplasma and Cytomegalovirus shows an association between infection and serious psychiatric disorders. Brain, Behavior and Immunity 79:152-158.

Caldas LA, de Souza W (2018). A window to Toxoplasma gondii egress. Pathogens 7(3):69.

Carey KL, Westwood NJ, Mitchison TJ, Ward GE (2004). A smallmolecule approach to studying invasive mechanisms of Toxoplasma gondii. Proceedings of the National Academy of Sciences of the USA 101(19):7433-7438.

Carneiro ACAV, Andrade GM, Costa JGL, Pinheiro BV, VasconcelosSantos DV, Ferreira AM, Vitor RWA (2013). Genetic characterization of Toxoplasma gondii revealed highly diverse genotypes for isolates from newborns with congenital toxoplasmosis in southeastern Brazil. Journal of Clinical Microbiology 51(3):901-907.

Chaichan P, Mercier A, Galal L, Mahittikorn A, Ariey F, Morand S, Dardé ML(2017). Geographical distribution of Toxoplasma gondii genotypes in Asia: A link with neighboring continents. Infection, Genetics and Evolution 53:227-238.

Cheng W, Wang C, Xu T, Liu F, Pappoe F, Luo Q, Shen J (2017). Genotyping of polymorphic effectors of Toxoplasma gondii isolates from China. Parasites and Vectors 10(1):1-8.

Colli CM, Rubinsky-Elefant G, Paludo ML, Falavigna DL, Guilherme E V, Mattia S, Falavigna-Guilherme AL (2010). Serological, clinical and epidemiological evaluation of toxocariasis in urban areas of south Brazil. Revista do Instituto de Medicina Tropical de Sao Paulo 52(2):69-74.

Corcino YL, Portillo JAC, Subauste CS (2019). Epidermal growth factor receptor promotes cerebral and retinal invasion by Toxoplasma gondii. Scientific Reports 9(1):1-12.

Daher W, Plattner F, Carlier MF, Soldati-Favre D (2010). Concerted action of two formins in gliding motility and host cell invasion by Toxoplasma gondii. PLoS Pathogens 6(10):e1001132.

Dard C, Fricker-Hidalgo H, Brenier-Pinchart MP, Pelloux H (2016). Relevance of and new developments in serology for toxoplasmosis. Trends in Parasitology 32(6):492-506.

Dardé ML (2008). Toxoplasma gondii, "new" genotypes and virulence. Parasite 15(3):366-371.

Deng H, Devleesschauwer B, Liu M, Li J, Wu Y, van der Giessen JW, Opsteegh M (2018). Seroprevalence of Toxoplasma gondii in pregnant women and livestock in the mainland of China: a systematic review and hierarchical meta-analysis. Scientific Reports 8(1):1-10.

Dlugonska H (2008). Toxoplasma rhoptries: unique secretory organelles and source of promising vaccine proteins for immunoprevention of toxoplasmosis. Journal of Biomedicine and Biotechnology 2008:632424.

Dong H, Su R, Lu Y, Wang M, Liu J, Jian F, Yang Y (2018). Prevalence, risk factors, and genotypes of Toxoplasma gondii in food animals and humans (2000-2017) from China. Frontiers in Microbiology 92108.

Döşkaya M, Caner A, Can H, İz SG, Gedik Y, Döşkaya AD, Gürüz $Y(2014)$. Diagnostic value of a Rec-ELISA using Toxoplasma gondii recombinant SporoSAG, BAG1, and GRA1 proteins in murine models infected orally with tissue cysts and oocysts. PloS One 9(9):e108329.

Döşkaya M, Liang L, Jain A, Can H, İz SG, Felgner PL, Gürüz AY (2018). Discovery of new Toxoplasma gondii antigenic proteins using a high throughput protein microarray approach screening sera of murine model infected orally with oocysts and tissue cysts. Parasites and Vectors 11(1):1-13.

Drinić M, Wagner A, Sarate P, Zwicker C, Korb E, Loupal G, Schabussova I (2017). Toxoplasma gondii tachyzoite-extract acts as a potent immunomodulator against allergic sensitization and airway inflammation. Scientific Reports 7(1):1-12.

Dubey JP (2002). Tachyzoite-induced life cycle of Toxoplasma gondii in cats. Journal of Parasitology 88(4):713-717.

Dubey JP (2006) Comparative infectivity of oocysts and bradyzoites of Toxoplasma gondii for intermediate (mice) and definitive (cats) hosts. Veterinary Parasitology 140(2):69-75.

Dubey JP (2008). The history of Toxoplasma gondii - the first 100 years. Journal of Eukaryotic Microbiology 55(6):467-475.

Dubey JP (2010). Toxoplasmosis of Animals and Man. 2nd ed. CRC Press: Boca Raton $340 \mathrm{p}$.

Dubremetz JF (2007). Rhoptries are major players in Toxoplasma gondii invasion and host cell interaction. Cellular Microbiology 
9(4):841-848.

El Bissati K, Chentoufi AA, Krishack PA, Zhou Y, Woods S, Dubey JP McLeod R (2016). Adjuvanted multi-epitope vaccines protect HLA-A* 11: 01 transgenic mice against Toxoplasma gondii. Journal of Clinical Investigation Insight 1(15):e85955.

El Bissati K, Zhou Y, Paulillo SM, Raman SK, Karch CP, Roberts CW, McLeod R(2017).Protein nanovaccine confers robust immunity against Toxoplasma. npj Vaccines 2(1):1-12.

El Hajj H, Lebrun M, Arold ST, Vial H, Labesse G, Dubremetz JF (2007). ROP18 is a rhoptry kinase controlling the intracellular proliferation of Toxoplasma gondii. PLOS Pathogens 3(2):e14.

Etheridge RD, Alaganan A, Tang K, Lou HJ, Turk BE,Sibley LD (2014). The Toxoplasma pseudokinase ROP5 forms complexes with ROP18 and ROP17 kinases that synergize to control acute virulence in mice. Cell Host and Microbe 15(5):537-550.

Evans R, Chatterton JMW, Ashburn D, Joss AWL, Ho-Yen DO (1999). Cell-culture system for continuous production of Toxoplasma gondii tachyzoites. European Journal of Clinical Microbiology and Infectious Diseases 18(12):879-884.

Fekkar A, Ajzenberg D, Bodaghi B, Touafek F, Le Hoang P, Delmas J, Paris L (2011). Direct genotyping of Toxoplasma gondii in ocular fluid samples from 20 patients with ocular toxoplasmosis: predominance of type II in France. Journal of Clinical Microbiology 49(4):1513-1517.

Ferguson DJP (2009). Toxoplasma gondii: 1908-2008, homage to Nicolle, Manceaux and Splendore. Memórias do Instituto Oswaldo Cruz 104(2):133-148.

Fisch D, Clough B, Frickel E-M (2019). Human immunity to Toxoplasma gondii. PLoS Pathogens 15(12):e1008097.

Flegr J, Horáček J (2018). Toxoplasmosis, but not borreliosis, is associated with psychiatric disorders and symptoms. Schizophrenia Research 197:603-604.

Flegr J, Stříž I (2011). Potential immunomodulatory effects of latent toxoplasmosis in humans. BMC Infectious Diseases 11:274.

Flegr J, Prandota J, Sovičková M, Israili ZH (2014). Toxoplasmosis -a global threat. Correlation of latent toxoplasmosis with specific disease burden in a set of 88 countries. PloS One 9(3):e90203.

Foroutan M, Rostami A, Majidiani H, Riahi SM, Khazaei S, Badri M, Yousefi E (2018). A systematic review and meta-analysis of the prevalence of toxoplasmosis in hemodialysis patients in Iran. Epidemiology and Health 40:e2018016.

Foroutan M, Ghaffarifar F, Sharifi Z, Dalimi A, Jorjani O (2019). Rhoptry antigens as Toxoplasma gondii vaccine target. Clinical and Experimental Vaccine Research 8(1):4-26.

Frenkel JK (1974). Pathology and pathogenesis of congenital toxoplasmosis. Bulletin of the New York Academy of Medicine 50(2):182-191.

Fuentes I, Rubio JM, Ramírez C, Alvar J (2001). Genotypic characterization of Toxoplasma gondii strains associated with human toxoplasmosis in Spain: direct analysis from clinical samples. Journal of Clinical Microbiology 39(4):1566-1570.

Galal L, Ajzenberg D, Hamidović A, Durieux MF, Dardé M L, Mercier A (2018). Toxoplasma and Africa: one parasite, two opposite population structures. Trends in Parasitology 34(2):140-154.

Gao JM, Xie YT, Xu ZS, Chen H, Hide G, Yang TB, Lun ZR (2017). Genetic analyses of Chinese isolates of Toxoplasma gondii reveal a new genotype with high virulence to murine hosts. Veterinary Parasitology 241:52-60.

Garcia JL, Innes EA, Katzer F (2014). Current progress toward vaccines against Toxoplasma gondii. Vaccine: Development and Therapy 4:23-37.

Gigley JP (2016). The diverse role of NK cells in immunity to Toxoplasma gondii infection. PLoS Pathogens 12(2):e1005396.

Gilot-Fromont E, Lélu M, Dardé ML, Richomme C, Aubert D, Afonso E,Villena I (2012). The life cycle of Toxoplasma gondii in the natural environment. In: Djaković OD (Ed.), Toxoplasmosis - Recent Advances. InTech Open: London pp. 3-34.

Gomez CA, Budvytyte LN, Press C, Zhou L, McLeod R, Maldonado Y, Contopoulos-Ioannidis DG (2018). Evaluation of three point-of-care tests for detection of toxoplasma immunoglobulin IgG and IgM in the United States: proof of concept and challenges. In Open Forum
Infectious Diseases 5(10): 215

Gomez CA, Sahoo MK, Kahn GY, Zhong L, Montoya JG, Pinsky BA, Doan T (2019). Dual-target, real-time PCR for the diagnosis of intraocular Toxoplasma gondii infections. British Journal of Ophthalmology 103(4):569-572.

Gov L, Karimzadeh A, Ueno N, Lodoen MB (2013). Human innate immunity to Toxoplasma gondii is mediated by host caspase-1 and ASC and parasite GRA15. MBio 4(4):e00255-13.

Grzybowski MM, Gatkowska JM, Dziadek B, Dzitko K, Długońska H (2015). Human toxoplasmosis: a comparative evaluation of the diagnostic potential of recombinant Toxoplasma gondii ROP5 and ROP18 antigens. Journal of Medical Microbiology 64(10):1201-1207.

Hajissa K, Zakaria R, Suppian R,Mohamed Z (2019). Epitope-based vaccine as a universal vaccination strategy against Toxoplasma gondii infection: a mini-review. Journal of Advanced Veterinary and Animal Research 6(2):174.

Hakimi MA, Olias P, Sibley LD (2017).Toxoplasma effectors targeting host signaling and transcription. Clinical Microbiology Reviews 30(3):615-645.

Hamilton CM, Black L, Oliveira S, Burrells A, Bartley P M, Melo RPB, Katzer $F$ (2019). Comparative virulence of Caribbean, Brazilian and European isolates of Toxoplasma gondii. Parasites and Vectors 12(1):1-10.

Hampton MM (2015). Congenital toxoplasmosis: a review. Neonatal Network 34(5):274-278.

Hill D, Dubey JP (2002). Toxoplasma gondii: transmission, diagnosis and prevention. Clinical Microbiology and Infection 8(10):634-640.

Hou B, Benson A, Kuzmich L, DeFranco AL, Yarovinsky F (2010). Critical coordination of innate immune defense against Toxoplasma gondii by dendritic cells responding via their Toll-like receptors. Proceedings of the National Academy of Sciences 108(1):278-283.

Hu LY, Zhang NZ, Zhang FK, Wang M, Gao Q, Wang JL, Zhu X Q (2017). Resistance to Chronic Toxoplasma gondii infection induced by a DNA vaccine expressing GRA16. BioMed Research International 2017:1295038.

Jones EJ, Korcsmaros T, Carding SR (2017). Mechanisms and pathways of Toxoplasma gondii transepithelial migration. Tissue Barriers 5(1):e1273865.

Jones JL, Kruszon-Moran D, Wilson M (2003). Toxoplasma gondii infection in the United States, 1999-2000. Emerging Infectious Diseases 9(11):1371-1374.

Jones JL, Kruszon-Moran D, Rivera HN, Price C, Wilkins PP (2014). Toxoplasma gondii seroprevalence in the United States 2009-2010 and comparison with the past two decades. American Journal of Tropical Medicine and Hygiene 90(6):1135-1139.

Kappe SH, Buscaglia CA, Bergman LW, Coppens I, Nussenzweig V (2004). Apicomplexan gliding motility and host cell invasion: overhauling the motor model. Trends in Parasitology 20(1):13-16.

Karch CP, Burkhard P (2016). Vaccine technologies: from whole organisms to rationally designed protein assemblies. Biochemical Pharmacology 120:1-14.

Khalili M, Mahami-Oskouei $M$, Shahbazi A, Safaiyan A, Mohammadzadeh-Gheshlaghi N, Mahami-Oskouei L (2018). The correlation between serum levels of anti-Toxoplasma gondii antibodies and the risk of diabetes. Iranian Journal of Parasitology 13(4):637.

Khan IA Smith KA, Kasper LH (1990). Induction of antigen-specific human cytotoxic $T$ cells by Toxoplasma gondii. Journal of Clinical Investigation 85(6):1879-1886.

Khattab HM, El Bassiouni SO, Abuelela MH, Abd Elsalam DO (2019). Seroprevalence of Toxoplasma gondii among a group of Egyptian patients with type I diabetes mellitus. Bulletin of the National Research Centre 43(1):1-7.

Kim JY, Ahn MH, Jun HS, Jung JW, Ryu JS, Min DY (2006). Toxoplasma gondii inhibits apoptosis in infected cells by caspase inactivation and NF-kB activation. Yonsei Medical Journal 47(6):862.

Kollu V, Magalhaes-Silverman M, Tricot G, Ince D (2018). Toxoplasma encephalitis following tandem autologous hematopoietic stem cell transplantation: a case report and review of the literature. Case Reports in Infectious Diseases 2018:9409121. 
Krishnamurthy S, Konstantinou EK, Young LH, Gold DA, Saeij JP 2017). The human immune response to Toxoplasma: autophagy versus cell death. PLoS Pathogens 13(3):e1006176.

Laing C, Blanchard N,McConkey GA (2020).Noradrenergic signaling and neuroinflammation crosstalk regulate Toxoplasma gondii-induced behavioral changes. Trends in Immunology 41(12):1072-1082.

Lee S-B, Lee T-G (2017). Toxoplasmic encephalitis in patient with acquired immunodeficiency syndrome. Brain Tumor Research and Treatment 5(1):34-36.

Li YX, Xin H, Zhang XY, Wei CY, Duan YH, Wang HF, Niu HT (2018). Toxoplasma gondii infection in diabetes mellitus patients in China: seroprevalence, risk factors, and case-control studies. BioMed Research International 2018:4723739.

Liu Q, Wang ZD, Huang SY, Zhu XQ (2015). Diagnosis of toxoplasmosis and typing of Toxoplasma gondii. Parasites and Vectors 8:292.

Liu Y, Cao A, Li Y, Li X, Cong H, He S, Zhou H (2017). Immunization with a DNA vaccine encoding Toxoplasma gondii Superoxide dismutase (TgSOD) induces partial immune protection against acute toxoplasmosis in BALB/c mice. BMC Infectious Diseases 17(1):403.

Luma HN, Tchaleu BC, Mapoure YN, Temfack E, Doualla MS, Halle MP, Joko HA, Koulla-Shiro S (2013). Toxoplasma encephalitis in HIVIAIDS patients admitted to the Douala general hospital between 2004 and 2009: a cross sectional study. BMC Research Notes 6:146.

Majidiani H, Dalvand S, Daryani A, Galvan-Ramirez MDLL, ForoutanRad M (2016). Is chronic toxoplasmosis a risk factor for diabetes mellitus? A systematic review and meta-analysis of case-control studies. Brazilian Journal of Infectious Diseases 20(6):605-609.

Maldonado YA, Read JS (2017) Committee on Infectious Diseases. Diagnosis, treatment, and prevention of congenital toxoplasmosis in the United States. Pediatrics 139(2).

Mammari N, Halabi MA, Yaacoub S, Chlala H, Dardé ML, Courtioux B (2019). Toxoplasma gondii modulates the host cell responses: an overview of apoptosis pathways. BioMed Research International, 2019:6152489.

McConkey GA, Martin HL, Bristow GC, Webster JP (2013).Toxoplasma gondii infection and behaviour-location, location, location?. Journal of Experimental Biology 216(1):113-119.

McFarland MM, Bartlett M, Davis P (2016). Toxoplasmic encephalitis. In: Encephalitis. Avid Science: Telangana pp. 2-52.

Menard KL, Haskins BE, Colombo AP,Denkers EY (2018). Toxoplasma gondii manipulates expression of host long noncoding RNA during intracellular infection. Scientific reports 8(1):1-14.

Mohamed K, Ahmed AA, Elrayah IE (2013). Prevalence and risk factors for Toxoplasma gondii infection in humans from Khartoum State, Sudan. International Journal of Public Health and Epidemiology 2(3):60-66.

Mohraz M, Mehrkhani F, Jam S, SeyedAlinaghi SA, Sabzvari D, Fattahi F, Hajiabdolbaghi M (2011). Seroprevalence of toxoplasmosis in HIV+/AIDS patients in Iran. Acta Medica Iranica 49(4):213-218.

Montoya JG (2002). Laboratory diagnosis of Toxoplasma gondii infection and toxoplasmosis. Journal of Infectious Diseases 185 (Suppl. 1):S73-S82.

Morris MI, Fischer SA, Ison MG (2010). Infections transmitted by transplantation. Infectious Disease Clinics 24(2):497-514.

Morrison DA, Höglund J (2005). Testing the hypothesis of recent population expansions in nematode parasites of human-associated hosts. Heredity 94(4):426-434.

Muluye D, Wondimeneh Y, Belyhun Y, Moges F, Endris M, Ferede G, ... Negese D (2013). Prevalence of Toxoplasma gondii and associated risk factors among people living with HIV at Gondar University Hospital, Northwest Ethiopia. International Scholarly Research Notices, 2013:123858.

Ngô HM, Zhou Y, Lorenzi H, Wang K, Kim TK, Zhou Y, McLeod R (2017). Toxoplasma modulates signature pathways of human epilepsy, neurodegeneration and cancer. Scientific Reports 7(1):1-32.

Patel R, Paya CV (1997). Infections in solid-organ transplant recipients. Clinical Microbiology Reviews 10(1):86-124.

Pena HFJ, Vitaliano SN, Beltrame MAV, Pereira FEL, Gennari SM, Soares RM (2013). PCR-RFLP genotyping of Toxoplasma gondii from chickens from Espirito Santo state, Southeast region, Brazil: new genotypes and a new SAG3 marker allele. Veterinary Parasitology 192(3):111-117.

Petit-Jentreau L, Glover C, Coombes JL (2018). Parasitized Natural Killer cells do not facilitate the spread of Toxoplasma gondii to the brain. Parasite Immunology 40(4):e12522.

Pierog PL, Zhao Y, Singh S, Dai J, Yap GS,Fitzgerald-Bocarsly P (2018).Toxoplasma gondii inactivates human plasmacytoid dendritic cells by functional mimicry of IL-10. Journal of Immunology 200(1):186-195.

Pinzan CF, Sardinha-Silva A, Almeida F, Lai L, Lopes CD, Lourenço EV, Roque-Barreira MC (2015). Vaccination with recombinant microneme proteins confers protection against experimental toxoplasmosis in mice. PloS One 10(11):e0143087.

Pleyer U, Schlüter D, Mänz M (2014). Ocular toxoplasmosis: recent aspects of pathophysiology and clinical implications. Ophthalmic Research 52(3):116-123.

Pollard AM , Knoll LJ, Mordue DG (2009). The role of specific Toxoplasma gondii molecules in manipulation of innate immunity. Trends in Parasitology 25(11):491-494.

Rajapakse S, Weeratunga P, Rodrigo C, de Silva NL, Fernando SD (2017). Prophylaxis of human toxoplasmosis: a systematic review. Pathogens and Global Health 111(7):333-342.

Randall LM, Hunter CA (2011). Parasite dissemination and the pathogenesis of toxoplasmosis. European Journal of Microbiology and Immunology 1(1):3-9.

Rasti S, Behrashi M, Kazemi B, Fatahian A, Mousavi G, Namakchian M (2012). Diagnosis of congenital toxoplasmosis by polymerase chain reaction. Indian Journal of Medical Microbiology 30(2):251.

Robert-Gangneux F, Dardé M-L (2012). Epidemiology of and diagnostic strategies for toxoplasmosis. Clinical Microbiology Reviews 25(2):264-296

Roberts F, Mets MB, Ferguson DJ, O'Grady R, O'Grady C, Thulliez P, McLeod R (2001). Histopathological features of ocular toxoplasmosis in the fetus and infant. Archives of Ophthalmology 119(1): 51-58.

Rothova A (2003). Ocular manifestations of toxoplasmosis.Current Opinion in Ophthalmology 14(6):384-388

Saki J, Mohammadpour N, Moramezi F, Khademvatan S (2015). Seroprevalence of Toxoplasma gondii in women who have aborted in comparison with the women with normal delivery in Ahvaz, southwest of Iran. The Scientific World Journal 2015:764369.

Sander V, Angel SO,Clemente M (2018). A comprehensive review of Toxoplasma gondii biology and host-cell interaction: challenges for a plant-based vaccine. Prospects of Plant-Based Vaccines in Veterinary Medicine pp. 89-120.

Sasai M, Pradipta A, Yamamoto M (2018). Host immune responses to Toxoplasma gondii. International Immunology 30(3):113-119.

Schaefer JJ, White HA, Schaaf SL, Mohammed HO,Wade SE (2012). Chimeric protein A/G conjugate for detection of anti-Toxoplasma gondii immunoglobulin $\mathrm{G}$ in multiple animal species. Journal of Veterinary Diagnostic Investigation 24(3):572-575.

Schlüter D, Barragan A (2019). Advances and challenges in understanding cerebral toxoplasmosis. Frontiers in Immunology 10:242.

Schwartz BS (2013). Parasitic infections in solid organ transplantation. American Journal of Transplantation 13(Suppl. 4):280-303.

Serranti D, Buonsenso D, Valentini P (2011). Congenital toxoplasmosis treatment. European Review for Medical and Pharmacological Sciences 15(2):193-198.

Sher A, Tosh K, Jankovic D (2017). Innate recognition of Toxoplasma gondii in humans involves a mechanism distinct from that utilized by rodents. Cellular and Molecular Immunology 14(1):36-42.

Shimokawa PT, Targa LS, Yamamoto L, Rodrigues JC, Kanunfre KA, Okay TS (2016). HLA-DQA1/B1 alleles as putative susceptibility markers in congenital toxoplasmosis. Virulence 7(4):456-464.

Shwab EK, Saraf P, Zhu XQ, Zhou DH, McFerrin BM, Ajzenberg DSuC. (2018). Human impact on the diversity and virulence of the ubiquitous zoonotic parasite Toxoplasma gondii. Proceedings of the National Academy of Sciences of the USA 115(29):E6956-E6963.

Soares JAS, Caldeira AP (2019). Congenital toxoplasmosis: the 
challenge of early diagnosis of a complex and neglected disease. Revista da Sociedade Brasileira de Medicina Tropical 52:e20180228.

Sommerville C, Richardson JM, Williams RA, Mottram JC, Roberts C W, Alexander J, Henriquez FL (2013). Biochemical and immunological characterization of Toxoplasma gondii macrophage migration inhibitory factor. Journal of Biological Chemistry 288(18):1273312741.

Sutterland AL, Fond G, Kuin A, Koeter MWJ, Lutter R, Van Gool T, De Haan L (2015). Beyond the association. Toxoplasma gondii in schizophrenia, bipolar disorder, and addiction: systematic review and meta-analysis. Acta Psychiatrica Scandinavica 132(3):161-179.

Szabo EK, Finney CAM (2017). Toxoplasma gondii: one organism, multiple models. Trends in Parasitology 33(2):113-127.

Takemae H, Sugi T, Kobayashi K, Gong H, Ishiwa A, Recuenco FC, Kato K (2013). Characterization of the interaction between Toxoplasma gondii rhoptry neck protein 4 and host cellular $\beta$-tubulin. Scientific Reports 3(1):1-9.

Tenter AM (2009). Toxoplasma gondii in animals used for human consumption. Memórias do Instituto Oswaldo Cruz 104(2):364-369.

Tosh KW, Mittereder L, Bonne-Annee S, Hieny S, Nutman TB, Singer S M, Jankovic D (2016). The IL-12 response of primary human dendritic cells and monocytes to Toxoplasma gondii is stimulated by phagocytosis of live parasites rather than host cell invasion. Journal of Immunology 196(1):345-356.

University of Guelph Centre for Public Health and Zoonoses (2009). Toxoplasma for Public Health Personnel. Available at: https://www.wormsandgermsblog.com/files/2008/04/M3-ToxoplasmaPHP1.pdf. Last updated 23 April 2009.

Wallon M, Peyron F (2018). Congenital toxoplasmosis: a plea for a neglected disease. Pathogens 7(1):25.

Wang D, Liu Y, Jiang T, Zhang G, Yuan G, He J, Yang N (2016). Seroprevalence and genotypes of Toxoplasma gondii isolated from pigs intended for human consumption in Liaoning province, northeastern China. Parasites and Vectors 9(1):1-5.

Wang T, Yin H, Li Y, Zhao L, Sun X, Cong H (2017). Vaccination with recombinant adenovirus expressing multi-stage antigens of Toxoplasma gondii by the mucosal route induces higher systemic cellular and local mucosal immune responses than with other vaccination routes. Parasite 24:12.

Weiss LM, Kim K (2000). The development and biology of bradyzoites of Toxoplasma gondii. Frontiers in Bioscience 5:D391-405.

Weiss LM, Dubey JP (2009). Toxoplasmosis: a history of clinical observations. International Journal for Parasitology 39(8):895-901.

White SL, Rawlinson W, Boan P, Sheppeard V, Wong G, Waller K, Ison $M$ (2018). Infectious disease transmission in solid organ transplantation: donor evaluation, recipient risk, and outcomes of transmission. Transplantation Direct 5(1).

World Health Organization (WHO) (2015). Toxoplasmosis Fact Sheet. World Health Organization: Geneva. Available at: https://www.euro.who.int/_data/assets/pdf_file/0011/294599/Factsh eet-Toxoplasmosis-en.pdf
Wilking H, Thamm M, Stark K, Aebischer T, Seeber F (2016) Prevalence, incidence estimations and risk factors of Toxoplasma gondii infection in Germany: a representative, cross-sectional, serological study. Scientific Reports 6(1):1-9.

Yamamoto JH, Lima Vallochi A, Silveira C, Kalil Filho J, Nussenblatt RB, Cunha-Neto E, Vicente Rizzo L (2000). Discrimination between patients with acquired toxoplasmosis and congenital toxoplasmosis on the basis of the immune response to parasite antigens. Journal of Infectious Diseases 181(6):2018-2022.

Yıldız Ç Akkar OB, Karakuş S, Cetin A (2015). Congenital toxoplasmosis. Basic and Clinical Sciences 1:62-69.

Zhang NZ, Chen J, Wang M, Petersen E, Zhu XQ (2013). Vaccines against Toxoplasma gondii: new developments and perspectives. Expert Review of Vaccines 12(11):1287-1299.

Zhang Z, Li Y, Wang M, Xie Q, Li P, Zuo S, Wang S (2018). Immune protection of rhoptry protein 21 (ROP21) of Toxoplasma gondii as a DNA vaccine against toxoplasmosis. Frontiers in Microbiology 9: 909.

Zhang Z, Li Y, Xie Q, Li P, Nan X, Kong L, Wang S (2019). The molecular characterization and immunity identification of rhoptry protein 22 of Toxoplasma gondii as a DNA vaccine candidate against toxoplasmosis. Journal of Eukaryotic Microbiology 66(1):147-157. 